\title{
A Compact Triple Band Antenna for Military Satellite Communication, Radar and Fifth Generation Applications
}

\author{
Doae El Hadri'1, Asmaa Zugari², Alia Zakriti', Mohssine El Ouahabi1 and Mohamed Taouzari ${ }^{3}$ \\ ${ }^{1}$ Laboratory of Sciences and Advanced Technology, Department of Civil and Industrial Sciences and Technologies, National School of Applied \\ Sciences, Abdelmalek Essaâdi University, Tetouan, Morocco \\ ${ }^{2}$ Information and Telecommunication system Laboratory, FS, Abdelmalek Essaâdi University, Tetouan, Morocco \\ ${ }^{3}$ Laboratory LISA, National School of Applied Sciences, Hassan $1^{\text {st }}$ University, Berrechid, Morocco \\ Corresponding author: Doae El Hadri (e-mail: doae93@gmail.com).
}

\begin{abstract}
A compact triple band antenna by using etching slots technique in the radiation element is presented in this paper. The proposed antenna is designed to target three different frequencies: $7.5 \mathrm{GHz}$ (military satellite communication), $9 \mathrm{GHz}$ (radar applications) and $28 \mathrm{GHz}$ (fifth generation applications). The fabricated prototype of the antenna has overall dimensions of $13 \times 12.8 \times 1.6 \mathrm{~mm}^{3}$. To validate the results of the simulation, measurements have been performed. The bandwidths at $-10 \mathrm{~dB}$ are $259 \mathrm{MHz}$ (7.435-7.695 MHz), $355 \mathrm{MHz}(8.86-9.221 \mathrm{MHz})$ and $2.67 \mathrm{GHz}(26.79-29.433 \mathrm{GHz})$. Furthermore, the suggested antenna provides a gain of $3.96 \mathrm{dBi}, 3.05 \mathrm{dBi}$ and $5.86 \mathrm{dBi}$ at $7.5 \mathrm{GHz}, 9 \mathrm{GHz}$ and $28 \mathrm{GHz}$ respectively. Therefore, the results demonstrate that the proposed triple band antenna can be used for military satellite communication, radar applications and is a good candidate for the future $5 \mathrm{G}$ applications.
\end{abstract}

INDEX TERMS Etching slots, fifth generation, radar application, triple band antenna.

\section{INTRODUCTION}

A rapid technological development in the field of telecommunications, including wireless communication systems, mobile phones, satellites, radar applications (civil, military, aeronautics, maritime and meteorology...), etc. is noticeable. Wireless communication systems has developed enormously from the first generation $1 \mathrm{G}$ to the fifth generation 5G. The main characteristics and applications of $5 \mathrm{G}$ are detailed in [1], while the $5 \mathrm{G}$ services are described in [2]. The fifth generation, also known as IMT-2020, will use the millimeter wave frequency band, specifically the $28 \mathrm{GHz}$ frequency band because propagation losses at $28 \mathrm{GHz}$ are not significant compared to other frequencies in the millimeter wave band $[3,4]$. The essential point of the $5 \mathrm{G}$ is that it will respond to a large number of completely new challenges in industrial automation (industry 4.0).

The diversity of applications involves the integration of many antennas and the use of several bands. These challenges have led to a great focus on multi-band antennas that allow simultaneous coverage of different bands. The advantage of using these antennas is the reduction in the number of antennas on board by combining multiple applications on the same antenna. Therefore, the main goal of our work is the conception of a multiband antenna that has a high performance and small in size.
The different techniques used to obtain multi-band antennas are: metamaterial structure [5, 6], fractal technology [7 - 13] loading stubs $[14,15]$ and etching slots $[16,17]$.

There are various designs of multi-band antennas in the literature. In [18], a miniaturized dual-band planar monopole antenna, formed by a CPW feed line and a rectangular ring with a vertical strip was designed for WLAN and WiMAX wireless communication applications. In [19], a deca-band printed antenna for $4 \mathrm{G} / 5 \mathrm{G} /$ WLAN mobile phones is presented. The Hexadecagon Circular Patch (HDCP) dualband antenna is presented in [20] for $\mathrm{Ku}$ band for satellite communications. A tri-band compact printed antenna consists of a folded open stub, long and short L-shaped strips, and asymmetric trapezoid ground plane was proposed in [21] for WLAN and WiMAX applications. An O-shape multiband integrated wideband antenna for Bluetooth/WLAN applications was presented in [22]. Tripleband antenna for WLAN/WiMAX applications reported in [23] consists of two F-shaped slot radiators and a defected ground plane. A multiband monopole antenna, presented in [24] for Global System for Mobile Communication (GSM) and Wireless Local Area Network (WLAN) applications, is achieved by introduced Complementary Split Ring Resonators (CSRRs) and offset-fed microstrip line. In [25] a CPW fed multiband folded slot antenna for WLAN application is studied. 
In this work, a compact triple band antenna is proposed for military satellite communications $(7.5 \mathrm{GHz})$, radar $(9 \mathrm{GHz})$ and fifth generation applications $(28 \mathrm{GHz})$. In order to achieve multiband, the etching slots technique was used. The influence of each slot of the proposed antenna on the performance of the antenna in terms of reflection coefficient is studied and discussed. The size of the suggested antenna is $13 \times 12.8 \mathrm{~mm}^{2}$. It is fabricated on FR4 substrate $(\varepsilon=4.4$, $\mathrm{h}=1.6 \mathrm{~mm}$ ). The simulated results of the proposed triple band antenna are validated by experimental results and shown an acceptable agreement.

\section{ANTENNA DESIGN AND DIMENSIONS}

Fig. 1 illustrates the layout of the triple band antenna and the photograph of the fabricated antenna. The antenna is printed on a FR4 substrate with dielectric constant of 4.4 and thickness of $1.6 \mathrm{~mm}$. The total size of the triple band antenna is $13 \mathrm{~mm}$ $x 12.8 \mathrm{~mm}$. A microstrip line with length of $\mathrm{LF}=6 \mathrm{~mm}$ and width of $\mathrm{WF}=3 \mathrm{~mm}$ is used for feeding the proposed antenna. The ground plane and the patch are composed of copper material with $0.035 \mathrm{~mm}$ of thickness.

After a parametric study using CST Microwave Studio, the final dimensions of the proposed triple band antenna are: $\mathrm{WS}=13 \mathrm{~mm}, \mathrm{LS}=12.8 \mathrm{~mm}, \mathrm{WF}=3 \mathrm{~mm}, \mathrm{LF}=6 \mathrm{~mm}, \mathrm{WP}=12$ $\mathrm{mm}, \mathrm{LP}=5 \mathrm{~mm}, \mathrm{~L} 1=10 \mathrm{~mm}, \mathrm{~L} 2=4 \mathrm{~mm}, \mathrm{~L} 3=10 \mathrm{~mm}, \mathrm{~L} 4=4$ $\mathrm{mm}, \mathrm{W}=1 \mathrm{~mm}, \mathrm{~L}=1 \mathrm{~mm}, \mathrm{D}=3.3 \mathrm{~mm}$.

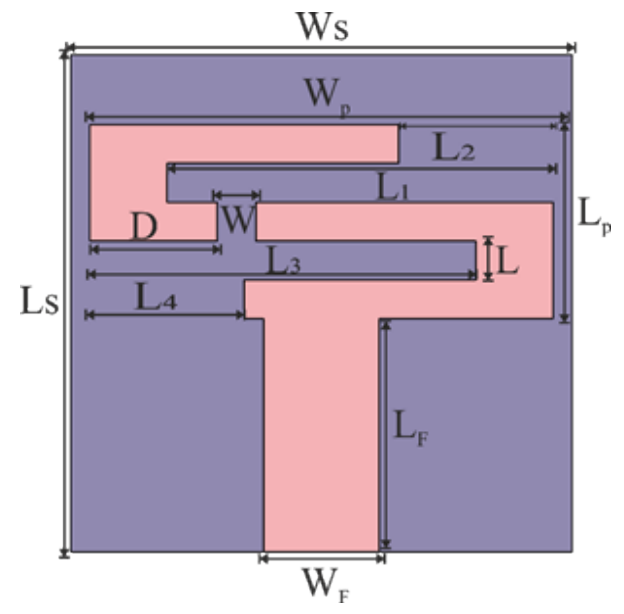

(a)

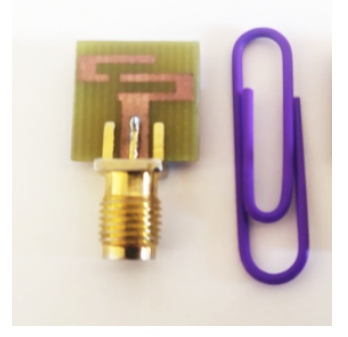

(b)

FIGURE 1. Geometry of the proposed triple band antenna (a), photograph of the fabricated antenna (b).

\section{DESIGN EVOLUTION}

The antenna design evolution steps to achieve the triple band operation for X-band (satellite communications and radar) and fifth generation applications is shown in Fig. 2. The proposed antenna is accomplished in four steps. In each step, a slot is introduced into the patch. Fig. 3 illustrate the reflection coefficient S1 1 at different steps of the design antenna.

In the first step we start with a conventional microstrip patch antenna, which produces resonance around $23 \mathrm{GHz}$. In the second step L-slot 1 is etched on the radiating element to generate double resonance frequencies of $7.5 \mathrm{GHz}$ and 25 GHz. In step 3, another L-slot 2 is etched to achieve triple band of $7.5 \mathrm{GHz}, 11 \mathrm{GHz}$ and $28 \mathrm{GHz}$. In order to attain impedance matching of the first band $(7.5 \mathrm{GHz})$ and shift the resonance frequency from $11 \mathrm{GHz}$ to $9 \mathrm{GHz}$, a slot 3 of $1 \mathrm{~mm}$ of width and $1 \mathrm{~mm}$ of high is cut in the patch (Step 4).

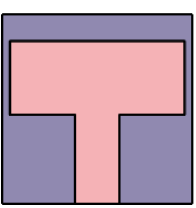

Step 1

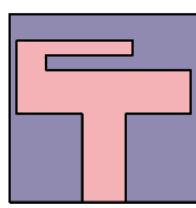

Step 2

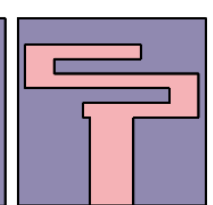

Step 3

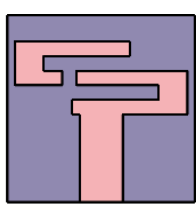

Step 4
FIGURE 2. Antenna geometry evolution for the proposed design.

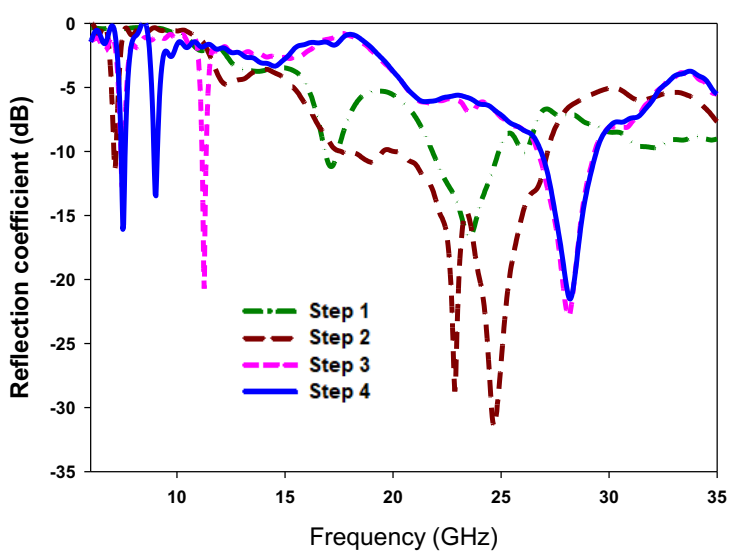

FIGURE 3. Simulated S11 against frequency for the various antenna configurations.

\section{PARAMETRIC STUDY}

The effect of geometrical parameters on the reflection coefficient of the proposed triple band antenna was analyzed using the CST Microwave Studio.

The simulated reflection coefficient as a function of lengths of L-Slot 1, L1 and L2, are illustrated in Fig. 4. As can be seen in Fig. 4 (a), when the value of $\mathrm{Ll}$ is varied from $11 \mathrm{~mm}$ to 9 $\mathrm{mm}$, the first resonance frequency increase while the second resonance frequency decrease. On the other hand, when the length L2 changes from $3 \mathrm{~mm}$ to $5 \mathrm{~mm}$, the first resonance frequency increase and the second resonance frequency is slightly affected as shown in Fig. 4 (b). The optimum values of L-slot 1 lengths are as follows: $\mathrm{L} 1=10 \mathrm{~mm}$ and L2=4 $\mathrm{mm}$. 


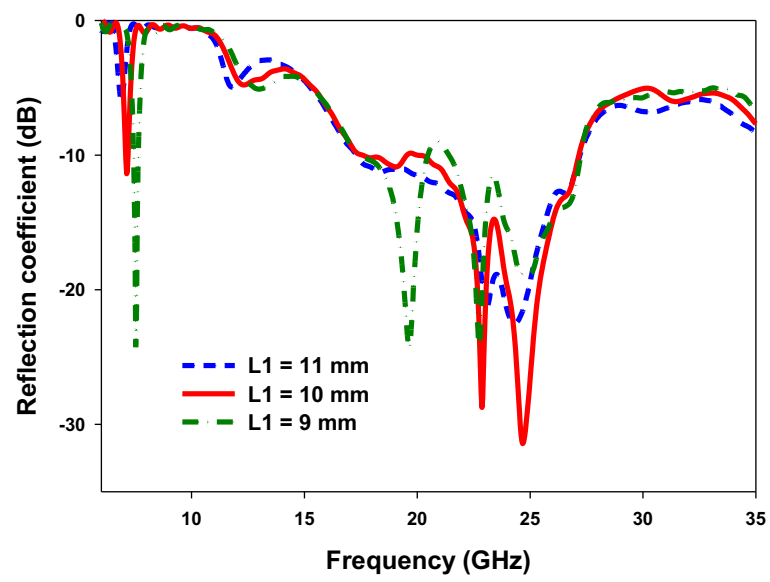

(a)

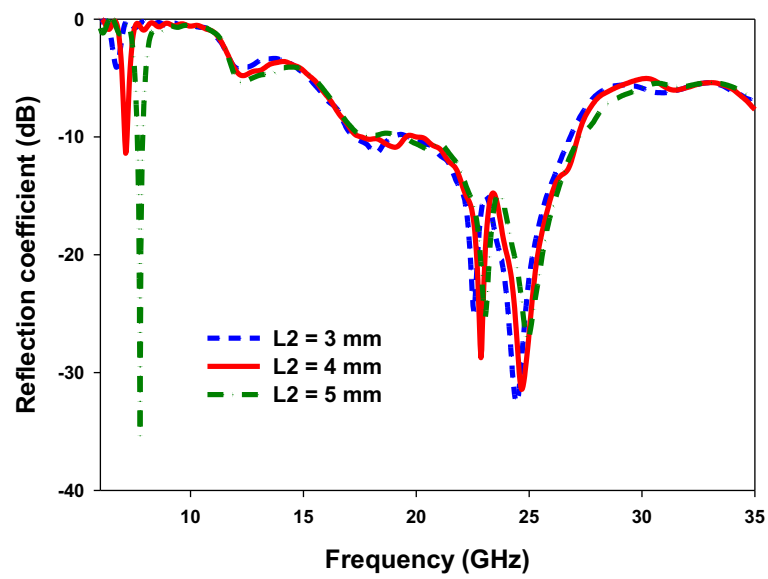

(b)

FIGURE 4. Reflection coefficient for various values of (a) L1 and (b) L2 lengths of $L_{-}$slot 1 .

Fig. 5 shown the reflection coefficient as a function of lengths of L-Slot 2 L3 and L4. It is clear that an increase in L3 causes a diminution in antenna reflection coefficient and the appearance of a new band. From Fig. 5 (a) we can see that the resonance frequency corresponds to the value $\mathrm{L} 3=10 \mathrm{~mm}$ is $28 \mathrm{GHz}$ (the fifth generation band), which is the desired frequency, we maintain this value of L3 and adjust L4 from 3 $\mathrm{mm}$ to $5 \mathrm{~mm}$. There is a slight variation in the level of adaptation in Fig. 5 (b). From this figure, we also notice that the second and third bands are adapted, therefore, to better adapt the first resonant frequency we will add a third slot.

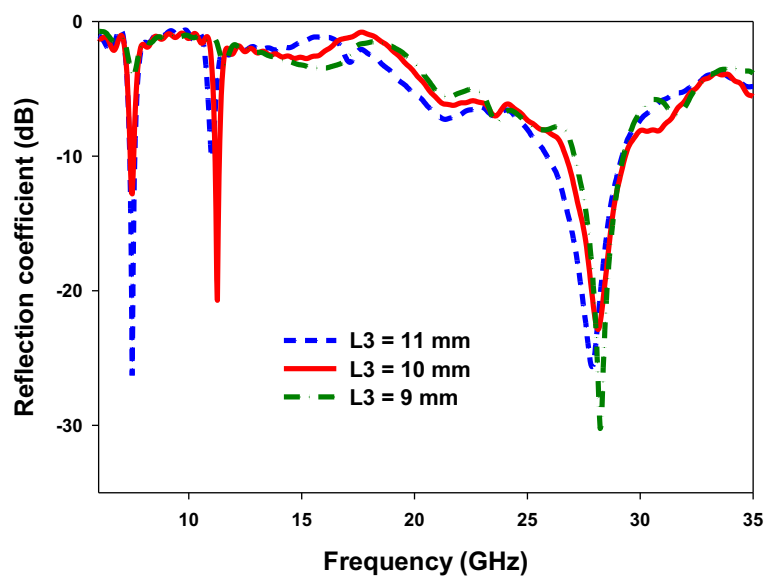

(a)

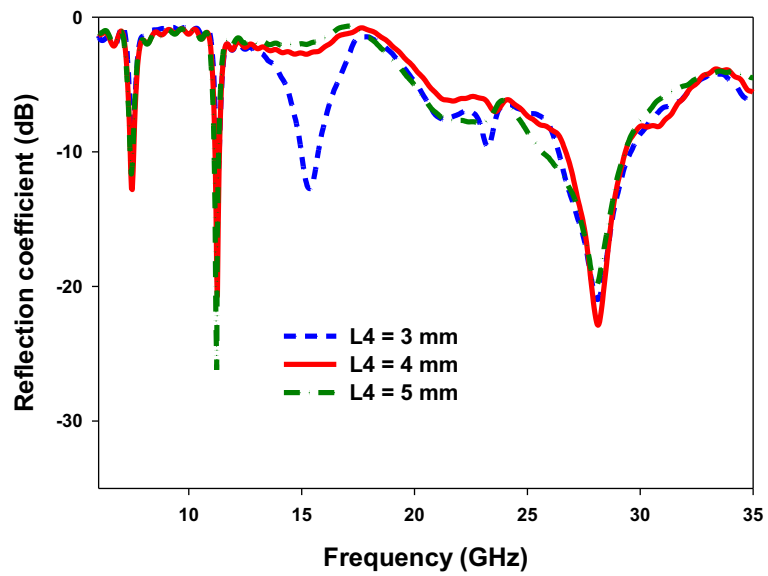

(b)

FIGURE 5. Reflection coefficient for various values of (a) L3 and (b) L4 lengths of $L \_$slot 2.

The effect of position "D" and width "W" of Slot 3 on the reflection coefficient are shown in Fig. 6. The D parameter is changed from $2.3 \mathrm{~mm}$ to $4.3 \mathrm{~mm}$, the optimal value for $\mathrm{D}$ is founded to be $3.3 \mathrm{~mm}$ for the best adaptation at the first band $7.5 \mathrm{GHz}$ (military satellite communication band). Decreasing the $\mathrm{D}$ parameter leads to a reduction in the resonant frequency of the second band. It is worth noting from Fig. 6 (a) that the variation of $\mathrm{D}$ parameter have no effect on the resonance frequency of $28 \mathrm{GHz}$. $\mathrm{D}=3.3 \mathrm{~mm}$ is kept and $\mathrm{W}$ is varied from 0.5 to 1.5 with a $0.5 \mathrm{~mm}$ step as shown in Fig. 6 (b) and it is noticed that as $\mathrm{W}$ increases the frequency of the second band also increases. The optimal value is $\mathrm{W}=1 \mathrm{~mm}$, which corresponds to $9 \mathrm{GHz}$ (Radar band). 


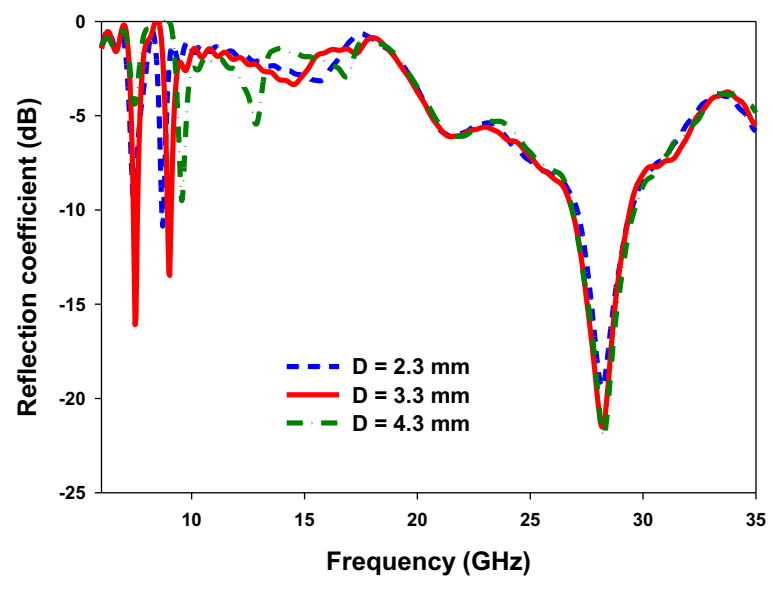

(a)

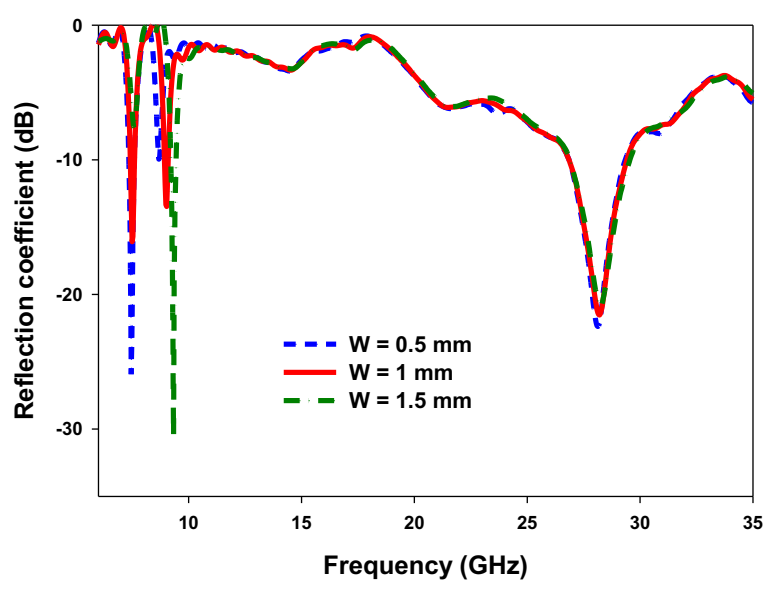

(b)

FIGURE 6. Effect of Slot 3 (a) variation of D parameter, (b) variation of W parameter.

\section{RESULTS AND DISCUSSIONS}

\section{A. REFLECTION COEFFICIENT}

In order to validate the simulation results, a prototype of the proposed triple band antenna is fabricated using LPKF machine Proto Mat E33. The reflection coefficient is measured using PNA-L Network Analyzer N5234A (10 MHz - 43.5 $\mathrm{GHz}$ ) and the simulated results are carried out by CST Microwave Studio. Fig. 7 demonstrates both the measured and simulated S11 results versus frequency for the proposed triple band antenna. The simulated impedance bandwidths for S11 $<-10 \mathrm{~dB}$ is $3.44 \%(7.435-7.695 \mathrm{GHz}) 4 \%(8.86-9.221 \mathrm{GHz})$ and $9.37 \%(26.79-29.433 \mathrm{GHz})$ at resonant frequencies 7.56 $\mathrm{GHz}, 9.016 \mathrm{GHz}$ and $28.156 \mathrm{GHz}$ respectively. An acceptable agreement can be observed between the simulated and measured results of the reflection coefficient of the proposed triple band antenna.

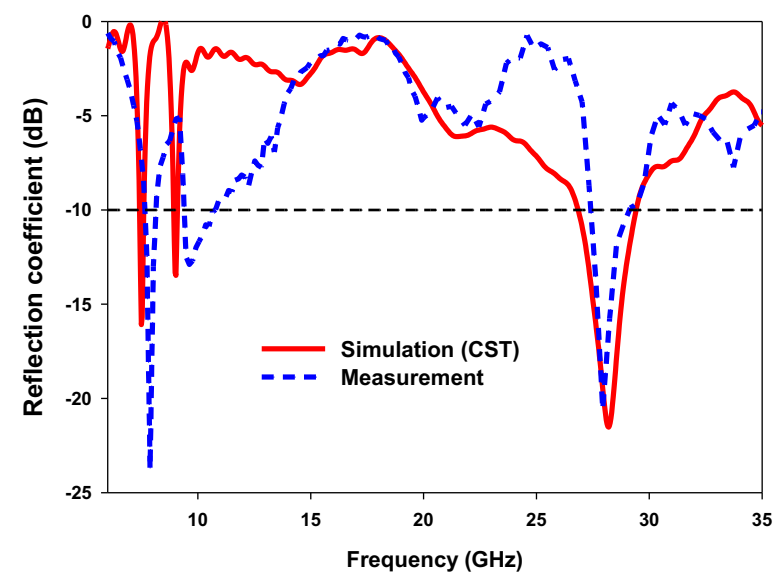

FIGURE 7. Measured and simulated results of reflection coefficient for the proposed antenna.

\section{B. SURFACE CURRENT DISTRIBUTIONS}

The observation of surface currents on the antenna structure provides a better understanding of how the current propagates over the radiating element. For this reason, Fig. 8 shows the surface current distribution of the proposed triple band antenna. The maximum surface currents is $35 \mathrm{~A} / \mathrm{m}$ at frequencies of $7.5 \mathrm{GHz}, 9 \mathrm{GHz}$ and $28 \mathrm{GHz}$.

Fig. 8 (a) shows that at $7.5 \mathrm{GHz}$, a strong distribution of surface currents appears on the radiating element and especially on the right side of the patch around the second Lslot 2. Which confirms that this slot is responsible for the creation of the $7.5 \mathrm{GHz}$ military satellite communication band. As shown in the Fig. 8 (b), at the second resonance frequency $9 \mathrm{GHz}$, the strongest currents are located in the upper part of the radiating element, confirming that this resonance is mainly related to this part of antenna which is situated to the left of the third slot (Slot 3). At $28 \mathrm{GHz}$ fifth generation band, the radiated current is concentrated at the edges of matching line as illustrated in the Fig. 8 (c).
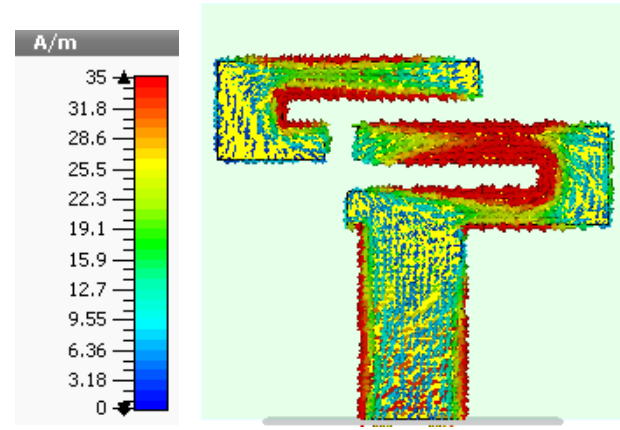

(a) 


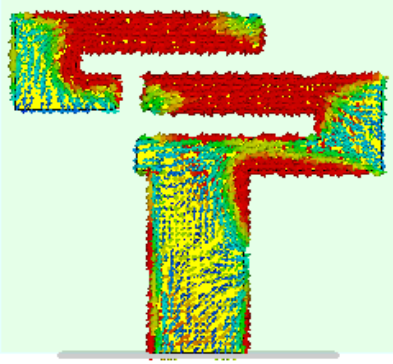

(b)

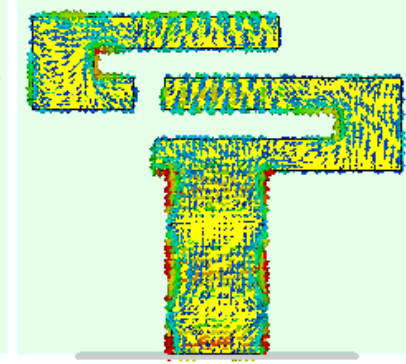

(c)

FIGURE 8. Surface current distribution of the proposed triple band antenna at $7.5 \mathrm{GHz}(\mathrm{a}), 9 \mathrm{GHz}$ (b) and $28 \mathrm{GHz}$ (c).

\section{RADIATION PATTERN, GAIN AND EFFICIENCY}

The radiation patterns of the proposed triple band antenna at resonance frequencies are studied. Fig. 9 shows the 3D radiation patterns at $7.56 \mathrm{GHz}, 9.016 \mathrm{GHz}$ and $28.156 \mathrm{GHz}$.
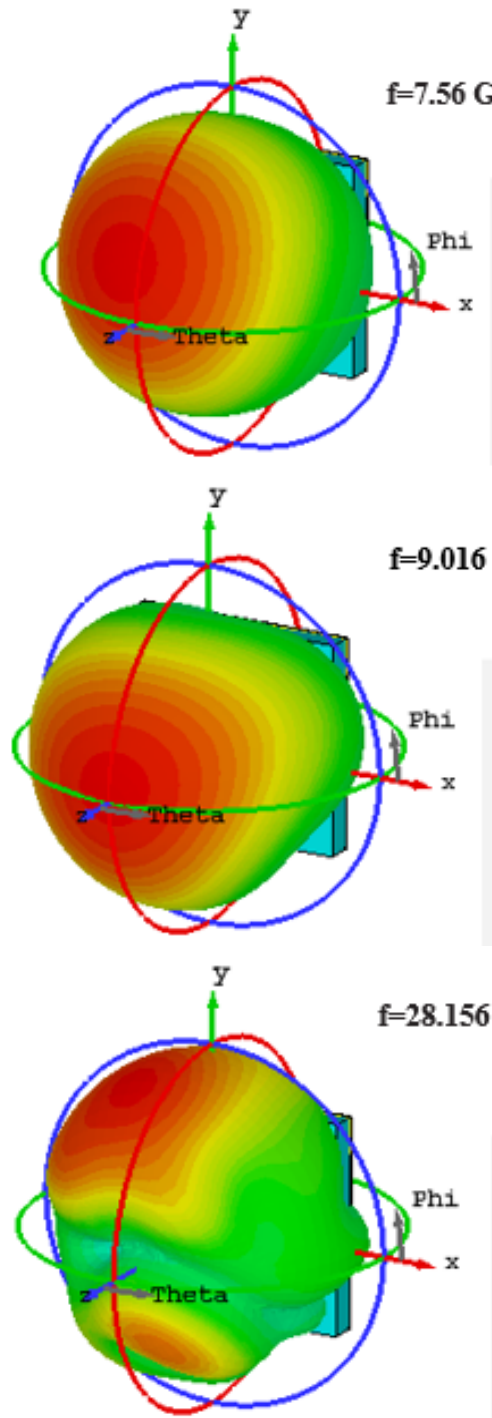

$-34.3$

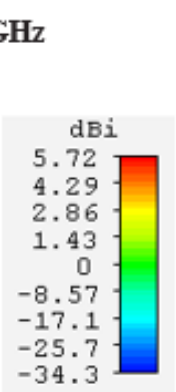

\section{$\mathrm{Hz}$}

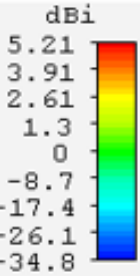

$-34.8$

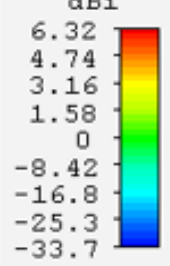

The Geozondas antenna measurement system that we have used is shown in Fig. 10. To measure the antenna radiation pattern, for the transmitting antenna a horn antenna was used, while the antenna under test functions as a receiving antenna. Note that when the transmitting and receiving antennas have the same polarization, it corresponds to co-polarization, and when the transmitting and receiving antennas have different polarizations, it corresponds to cross-polarization.

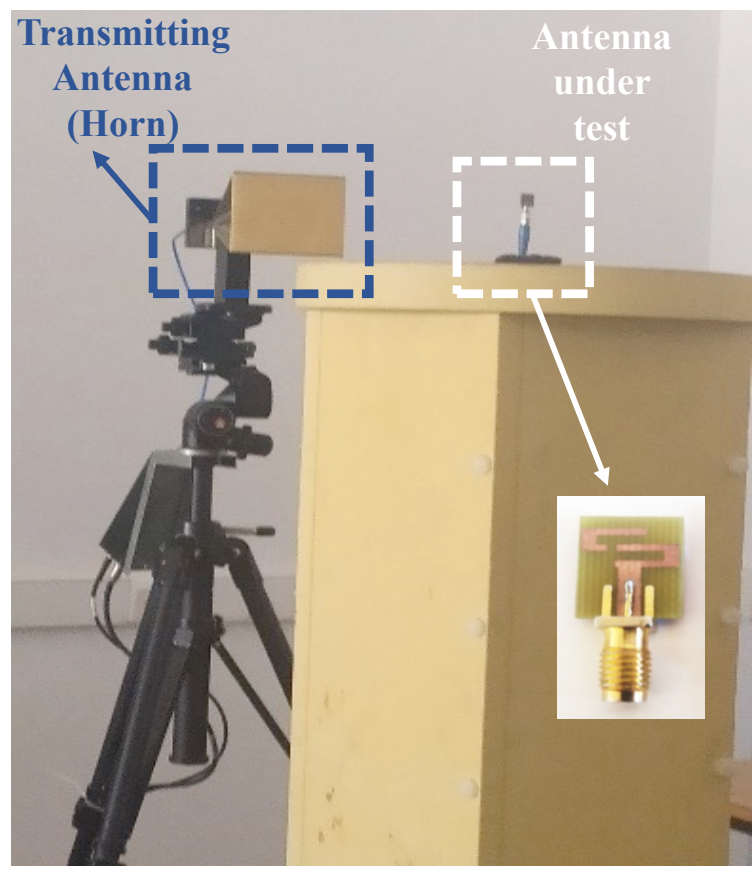

FIGURE 10. Measurement setup of the proposed antenna.

The simulated and measured far-field 2D radiation patterns of the proposed triple band antenna is illustrated in Fig. 11 (a) and Fig. 11 (b), in two principal planes: the elevation plane "E plane" (xz plane, phi=0) and azimuth plane "H plane" (xy plane, theta $=0$ ), co-polarization and cross-polarization at resonant frequencies $7.5 \mathrm{GHz}$ and $9 \mathrm{GHz}$. While, the measured far-field 2D radiation pattern of the proposed triple band antenna at $28 \mathrm{GHz}$ was not feasible, because the limited frequency of the Horn antenna used is $26 \mathrm{GHz}$ in our laboratory. Consequently, Fig. 11 (c) represents only the simulated radiation pattern at $28 \mathrm{GHz}$ frequency. From Fig. 11 it can be observed that the measured results are slightly difference compared to the simulated results, because the radiation pattern measurements are not carried out in an anechoic chamber. In addition, we can see from Fig. 11 that the cross-polarization is a little high due to the high thickness of the substrate used $(\mathrm{h}=1.6 \mathrm{~mm})[26]$. 

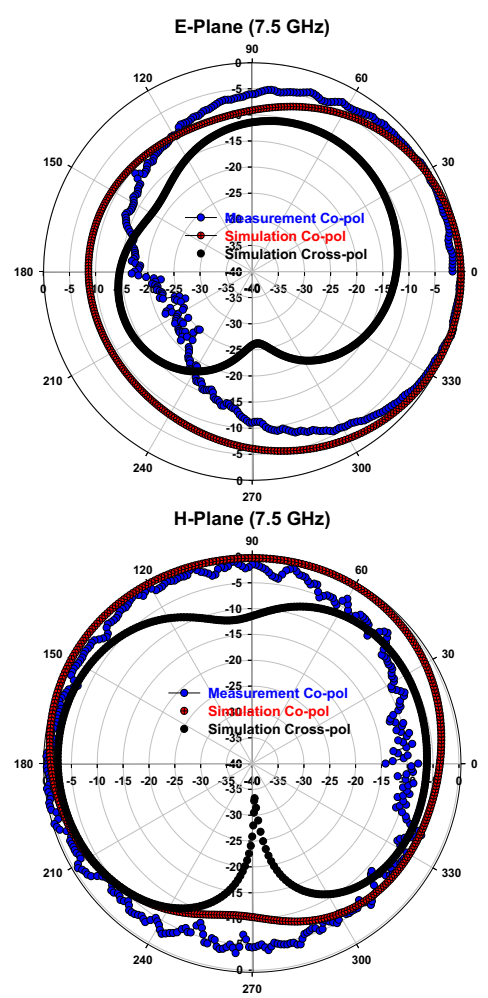

(a)
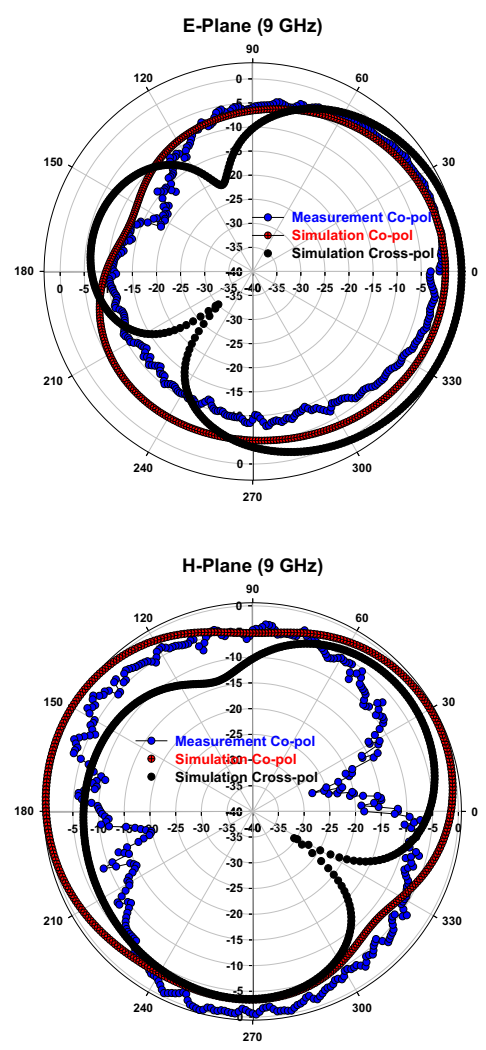

(b)
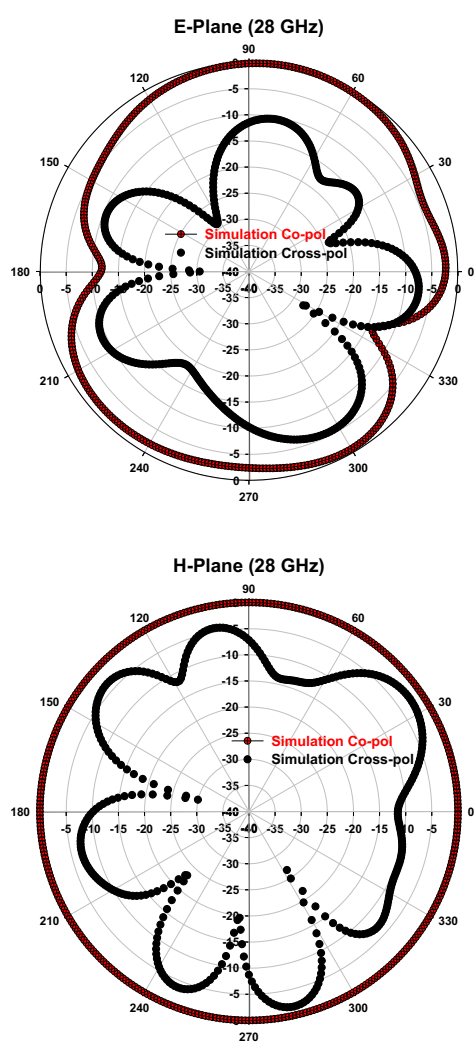

(c)

FIGURE 11. Radiation patterns of the proposed triple band antenna in $\mathrm{E}$ Plane and $\mathrm{H}$-Plane at $7.5 \mathrm{GHz}$ (a), $9 \mathrm{GHz}$ (b) and $28 \mathrm{GHz}$ (c).

The simulated gain and efficiency variation with the frequency are plotted in Fig. 12. It can be seen that the proposed antenna has radiation efficiency of $47 \%, 40 \%$ and $83 \%$ at the resonance frequencies $7.5 \mathrm{GHz}, 9.01 \mathrm{GHz}$ and 28.1 $\mathrm{GHz}$ respectively. The proposed antenna provides a gain of $3.96 \mathrm{dBi}$ at $7.5 \mathrm{GHz}, 3.05 \mathrm{dBi}$ at $9.01 \mathrm{GHz}$ and $5.86 \mathrm{dBi}$ at 28 GHz.

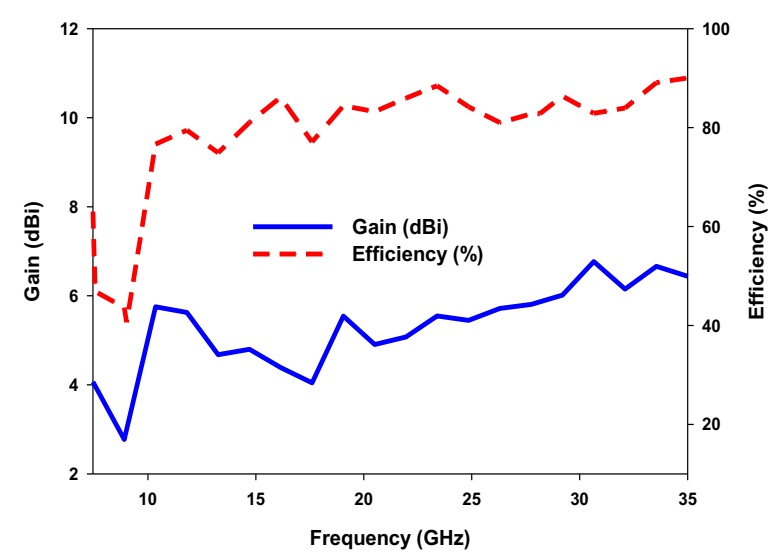

FIGURE 12. Gain and Radiation Efficiency of the proposed triple band antenna. 


\section{PERFORMANCE COMPARISON}

The proposed triple band antenna is compared with the previous reported antenna, and the comparison is indicated in Table I. This table comparing antennas performance in terms of size, resonant frequencies, gain achieved and also the technique used to obtain multiband. It is clearly observed that the proposed antenna is compact in size as compared to all the references listed in table 1 . In addition, the proposed antenna has a high gain.

TABLE I. Comparison of the Proposed Antenna and Already Reported Antenna.

\begin{tabular}{|c|c|c|c|c|}
\hline Ref & $\begin{array}{c}\text { Size } \\
\left(\mathrm{mm}^{2}\right)\end{array}$ & $\begin{array}{c}\text { Resonant } \\
\text { frequencies } \\
(\mathrm{GHz})\end{array}$ & $\begin{array}{l}\text { Gain } \\
(\mathrm{dBi})\end{array}$ & Technique \\
\hline \multirow{3}{*}{ P.S } & \multirow{3}{*}{$13 \times 12.8$} & 7.5 & 3.96 & \multirow{3}{*}{ Etching slots } \\
\hline & & 9 & 3.05 & \\
\hline & & 28 & 5.86 & \\
\hline \multirow{2}{*}[5]{} & \multirow{2}{*}{$30 \times 30$} & 2.7 & 1.49 & \multirow{2}{*}{$\begin{array}{c}\text { Metamaterial } \\
\text { structure }\end{array}$} \\
\hline & & 7.34 & 3.23 & \\
\hline \multirow{3}{*}[6]{} & \multirow{3}{*}{$31 \times 26.27$} & 3.4 & - & \multirow{3}{*}{$\begin{array}{c}\text { Metamaterial } \\
\text { structure }\end{array}$} \\
\hline & & 5.16 & - & \\
\hline & & 9.5 & - & \\
\hline \multirow{3}{*}{ [14] } & \multirow{3}{*}{$18 \times 34.5$} & 2.45 & - & \multirow{3}{*}{$\begin{array}{l}\text { Loading } \\
\text { stubs }\end{array}$} \\
\hline & & 5.5 & - & \\
\hline & & 7.5 & 3.2 & \\
\hline \multirow{4}{*}{ [15] } & \multirow{4}{*}{$16 \times 24$} & 3.44 & 2.46 & \multirow{4}{*}{$\begin{array}{l}\text { Loading } \\
\text { stubs }\end{array}$} \\
\hline & & 4.6 & 1.62 & \\
\hline & & 7.5 & 1.58 & \\
\hline & & 9.6 & 1.86 & \\
\hline \multirow{3}{*}{ [16] } & \multirow{3}{*}{$26 \times 23$} & 4.27 & - & \multirow{3}{*}{ Etching slots } \\
\hline & & 5.5 & - & \\
\hline & & 7.20 & 1 & \\
\hline \multirow{4}{*}{ [17] } & \multirow{4}{*}{$18 \times 22$} & 2.4 & 2.87 & \multirow{4}{*}{ Etching slots } \\
\hline & & 3.5 & 3.48 & \\
\hline & & 5.8 & 1.82 & \\
\hline & & 8 & 3.34 & \\
\hline \multirow{4}{*}{ [27] } & & 28 & 2.33 & \multirow{4}{*}{-} \\
\hline & $15.5 \times 14$ & 38 & 2.46 & \\
\hline & 5 & 40 & 1.69 & \\
\hline & & 67 & 2.17 & \\
\hline \multirow{2}{*}{ [28] } & \multirow{2}{*}{$60 \times 60$} & 3.5 & 7.51 & \multirow[b]{2}{*}{-} \\
\hline & & 7.5 & 3.14 & \\
\hline
\end{tabular}

\section{CONCLUSION}

A compact triple-band antenna is presented in this paper. The multiband is achieved by etching three slots on the radiating element. The triple band antenna has smaller size of $13 \times 12.8$ $\mathrm{mm}^{2}$ and can cover military satellite communication, radar and fifth generation bands. The proposed antenna was designed using CST Microwave Studio, fabricated on FR4 substrate with dielectric constant of 4.4 and thickness of $1.6 \mathrm{~mm}$ and then measured. The results show that the proposed antenna operates at $7.5 \mathrm{GHz}, 9 \mathrm{GHz}$ and $28 \mathrm{GHz}$ with a fractional bandwidth of $3.44 \%, 4 \%, 9.37 \%$ respectively. In addition, good radiation efficiency of more than $47 \%, 40 \%, 83 \%$ and gain of $3.96 \mathrm{dBi}, 3.05 \mathrm{dBi}, 5.86 \mathrm{dBi}$ are obtained. The antenna has the advantages of small in size, simple structure and multiband, which makes it a good candidate for X-band and fifth generation applications.

\section{ACKNOWLEDGMENT}

This work is carried out with the support of the CNRST within the framework of the Research Excellence Scholarship Program. The authors would like to thank Professor Jamal EL AOUFI from Laboratory of Aeronautical Telecommunication, Mohammed VI, International Academy of Civil Aviation, Casablanca, Morocco for his support with regards to the measure of the proposed antenna in his laboratory.

\section{REFERENCES}

[1] H. Mahmud, "Cellular Mobile Technologies ( $1 \mathrm{G}$ to 5G ) and Massive MIMO,” Int. J. Sci. Res., vol. 8, no. 7, pp. 929-937, 2019.

[2] H. Yu, H. Lee, and H. Jeon, "What is $5 \mathrm{G}$ ? Emerging $5 \mathrm{G}$ mobile services and network requirements," Sustainability, vol. 9, no. 10, pp. 1-22, 2017.

[3] C. K. Agubor, I. Akwukwuegbu, M. Olubiwe, and C. O. Nosiri, "A comprehensive review on the feasibility and challenges of millimeter wave in emerging 5G mobile communication," Adv. Sci. Technol. Eng. Syst., vol. 4, no. 3, pp. 138-144, 2019.

[4] T. S. Rappaport, Y. Xing, G. R. Maccartney, A. F. Molisch, E. Mellios, and J. Zhang, "Overview of Millimeter Wave Communications for Fifth-Generation (5G) Wireless Networks-With a Focus on Propagation Models," IEEE Trans. Antennas Propag., vol. 65, no. 12, pp. 6213-6230, 2017.

[5] A. Gupta, A. Patro, A. Negi, and A. Kapoor, "A compact dual-band metamaterial inspired antenna with virtual ground plane for WiMAX and satellite applications," Prog. Electromagn. Res. Lett., vol. 81, pp. 29-37, 2019.

[6] R. B. Rani and S. K. Pandey, "CSRR inspired conductor backed CPWfed monopole antenna for multiband operation," Prog. Electromagn. Res. C, vol. 70, pp. 135-143, 2016.

[7] G. Varamini, A. Keshtkar, N. Daryasafar, and M. N. Moghadasi, "Microstrip Sierpinski fractal carpet for slot antenna with metamaterial loads for dual-band wireless application," Int. J. Electron. Commun., vol. 84, pp. 93-99, 2018.

[8] Z. Yu, J. Yu, X. Ran, and C. Zhu, "A novel Koch and Sierpinski combined fractal antenna for $2 \mathrm{G} / 3 \mathrm{G} / 4 \mathrm{G} / 5 \mathrm{G} / \mathrm{WLAN} /$ navigation applications," Microw Opt Technol Lett, vol. 59, pp. 2147-2155, 2017.

[9] G. Srivatsun and S. Subha Rani, "Compact multiband planar fractal cantor antenna for wireless applications: An approach,” Int. J. Antennas Propag., vol. 2012, 2012.

[10] I. S. Bangi and J. S. Sivia, "Minkowski and Hilbert curves based hybrid fractal antenna for wireless applications," AEU - Int. J. Electron. Commun., vol. 85, pp. 159-168, 2018.

[11] K. J. Vinoy, K. A. Jose, V. K. Varadan, and V. V. Varadan, "Hilbert curve fractal antenna: A small resonant antenna for VHF/UHF applications," Microw. Opt. Technol. Lett., vol. 29, no. 4, pp. 215-219, 2001.

[12] G. Srivatsun and S. Subha Rani, "A compact wideband fractal cantor antenna for wireless applications," AEU - Int. J. Electron. Commun., vol. 65 , no. 9, pp. 719-723, 2011.

[13] I. S. Bangi and J. S. Sivia, "Moore, Minkowski and Koch Curves Based Hybrid Fractal Antenna for Multiband Applications," Wirel. Pers. Commun., vol. 108, no. 4, pp. 2435-2448, 2019.

[14] R. Zhi, M. Han, J. Bai, and W. Wu, "Miniature multiband antenna for WLAN and X-Band satellite communication applications," Prog. Electromagn. Res. Lett., vol. 75, pp. 13-18, 2018.

[15] X. Cao, Y. Xia, L. Wu, and L. Lang, "A compact quad-band ring stringshaped antenna,” AEU - Int. J. Electron. Commun., vol. 111, 2019.

[16] R. Pandeeswari, "Complimentary split ring resonator inspired meandered CPW-fed monopole antenna for multiband operation," Prog. Electromagn. Res. C, vol. 80, pp. 13-20, 2018.

[17] T. Liu, Y. Sun, J. Li, and J. Yu, "CPW-fed compact multiband monopole antenna for WLAN/WiMAX/X-band application," Prog. Electromagn. Res. Lett., vol. 87, pp. 105-113, 2019.

[18] A. Z. Manouare, S. Ibnyaich, D. Seetharamdoo, and A. EL Idrissi, "Design, fabrication and measurement of a miniaturized CPW-Fed planar monopole antenna using a single vertical strip for multi-band 
wireless applications,” J. Eng. Technol., vol. 7, no. 1, pp. 155-169, 2018.

[19] M. Yang, Y. Sun, and F. Li, "A Compact Wideband Printed Antenna for 4G/5G/WLAN Wireless Applications," Int. J. Antennas Propag., 2019.

[20] K. Kumar Naik and P. Amala Vijaya Sri, "Design of hexadecagon circular patch antenna with DGS at $\mathrm{Ku}$ band for satellite communications," Prog. Electromagn. Res. M, vol. 63, pp. 163-173, 2018.

[21] P. Osklang, C. Phongcharoenpanich, and P. Akkaraekthalin, "Triband Compact Printed Antenna for 2.4/3.5/5GHz WLAN/WiMAX Applications,” Int. J. Antennas Propag., 2019.

[22] K. Srivastava, A. Kumar, B. K. Kanaujia, and S. Dwari, "Multiband integrated wideband antenna for bluetooth/WLAN applications," AEU - Int. J. Electron. Commun., vol. 89, pp. 77-84, 2018.

[23] A. K. Gautam, L. Kumar, B. K. Kanaujia, and K. Rambabu, "Design of Compact F-Shaped Slot Triple-Band Antenna for WLAN/WiMAX Applications," IEEE Trans. Antennas Propag., vol. 64, no. 3, pp. 11011105,2016
[24] R. Samson Daniel, R. Pandeeswari, and S. Raghavan, "Offset-fed complementary split ring resonators loaded monopole antenna for multiband operations," AEU - Int. J. Electron. Commun., vol. 78, pp. 72-78, 2017

[25] L. Zheng and G. Wang, "Design of Triple-Frequency Folded Slot Antenna for 2.4/3.5/5.2/5.8-GHz WLAN Applications," Prog. Electromagn. Res. Lett., vol. 43, pp. 115-123, 2013.

[26] J. Huang, X. Zhang, S. Xie, W. Wu, and N. Yuan, "Suppression of cross-polarization of the microstrip integrated balun-fed printed dipole antenna," Int. J. Antennas Propag., vol. 2014, 2014.

[27] K. Y. Yazdandoost and I. Laakso, "EMF exposure analysis for a compact multi-band 5G antenna," Prog. Electromagn. Res. M, vol. 68, pp. 193-201, 2018.

[28] M. J. Rana and M. A. S. Mollah, "Numerical Study of a Loaded UAntenna for 3.5 GHz Mobile WiMAX and 7.5 GHz Military Satellite Communication Applications," in 16th Int'l Conf. Computer and Information Technology, Khulna, Bangladesh, 8-10 March 2014. 